\title{
Nuevo esquema de vacuna antimeningocóccica en niños
}

\author{
New meningococcal vaccine schedule in children
}

Alejandro Gabriel Catanzariti* y Ana Paula Gómez*

\begin{abstract}
Resumen
La enfermedad invasiva por meningococo trae aparejada una alta morbimortalidad. Se presenta habitualmente en forma de casos aislados o brotes epidémicos y afecta en la Argentina a 200 a 300 casos por año, principalmente en niños menores de cinco años de edad. Actualmente en nuestro país se encuentran disponibles dos vacunas que cubren los serotipos A, C, Y, W del meningococo (Menactra ${ }^{\circledR}$ y Menveo $^{\circledR}$ ). A partir de Marzo de 2015, el Ministerio de Salud de la Nación Argentina incorporó la vacunación universal contra meningococo, estableciendo un esquema con una dosis a los tres y cinco meses y un refuerzo a los 15 meses de vida; y una dosis única para los adolescentes, a los 11 años de edad.

\section{Abstract}

Invasive meningococcal disease results in high morbidity and mortality. It usually occurs in the form of isolated cases of epidemic outbreaks and affects 200 to 300 cases per year in Argentina, especially in children under five years of age. Vaccines covering meningococcal serotypes A, C, Y, W (Menactra ${ }^{\circledR}$ and Menveo $^{\circledR}$ ) are currently available in our country. Since March 2015 , the Argentine's Ministry of Health incorporated the universal vaccination against meningococcus, establishing a scheme with two doses at three and five months and a booster at 15 months of life; and a single dose for adolescents, at 11 years of age.
\end{abstract}

Catanzariti A, Gómez A. Nuevo esquema de vacuna antimeningocóccica en niños. Evid Act Pract Ambul. 2017;20(2):58.

Neisseria meningitidis es el agente causal de la enfermedad invasiva por meningococo (EIM), que se presenta principalmente, como bacteriemia, sepsis y meningoencefalitis.

La EIM trae aparejada alta morbimortalidad, el $100 \%$ de los casos requiere asistencia médica y hospitalización debido a su súbita y catastrófica evolución clínica. Es una de las enfermedades infectocontagiosas más graves y con mayor tasa de secuelas permanentes (pérdida de la audición, convulsiones, hidrocefalia, retraso madurativo neurológico, entre otras) por lo que requiere asistencia multidisciplinaria prolongada en caso de supervivencia ${ }^{1}$.

Se presenta habitualmente en forma de casos aislados, con mayor frecuencia en invierno y primavera, y periódicamente, en brotes epidémicos localizados o extendidos. En Argentina se registran 200 a 300 casos por año; afecta principalmente a los niños menores de cinco años y el mayor impacto en la población infantil se da en menores de 12 meses, con una incidencia de 14 casos cada 100.000 habitantes. Anualmente se registran 20 a 30 fallecidos por esta causa, lo que refleja una mortalidad del $10 \%{ }^{2}$.

Debido a todo esto la enfermedad por meningococo constituye un problema de salud pública.

La vacunación es una medida de prevención primaria eficaz para evitar la infección por meningococo.

De los trece serogrupos de meningococo, en la Argentina circulan cuatro (B, C, W e Y). Desde el 2007 la mayoría de los casos han sido causados por los serogrupos $\mathrm{B}$ y $\mathrm{W}^{2}$.
En la actualidad existen vacunas que son eficaces, seguras y pueden ser administradas a menores de dos años logrando alta respuesta inmunogénica ${ }^{3}$.

Se encuentran disponibles:

-Menveo ${ }^{\circledR}$ : vacuna polisacárida tetravalente $(A, C, Y, W)$ conjugada con la proteína CRM197, aprobada para su uso en adultos y en niños a partir de los dos meses de edad.

-Menactra ${ }^{\circledR}$ : vacuna polisacárida tetravalente $(A, C, Y, W)$ conjugada con la proteína transportadora modificada de toxoide tetánico, aprobada en adultos y niños a partir de los nueve meses de edad.

A partir de Marzo de 2015, en la Res. 10/2015 del Ministerio de Salud, se incorporó la vacuna contra meningococo al Programa Nacional de Control de Enfermedades Inmunoprevenibles; y ya se encuentra en el Calendario Nacional de Vacunación ${ }^{4-6}$.

El esquema propuesto en dicha resolución para niños mayores de tres meses es de tipo 2+1: una dosis a los tres y cinco meses y un refuerzo a los 15 meses de vida. En adolescentes el esquema es, en cambio, una dosis única a los 11 años de edad. El objetivo del esquema de dosis única para adolescentes, es disminuir la portación orofaríngea del meningococo provocando una baja en la incidencia de enfermedad en la población no vacunada.

Al ser incorporada al Programa Nacional de Control de Enfermedades Inmunoprevenibles y al Calendario Nacional de Vacunación, se garantiza su acceso gratuito y sin requerir orden médica para su administración a los niños comprendidos en la resolución, favoreciendo de esta manera el acceso a la vacuna.

\footnotetext{
Referencias

1.Almeida-González L, y col. Enfermedad por meningococo, Neisseria meningitidis: perspectiva epidemiológica, clínica y preventiva. Salud pública Méx. 2004 Oct;46(5):438-450. 1.Almeida-González L, y col. Enfermedad por meningococo, Neisseria meningitidis: perspectiva epidemiológica,
Disponible en: $\mathrm{http}: / /$ www.scielo.org.mx/scielo.php?script=sci_arttext\&pid=S0036-36342004000500010\&lng=es.

2. Sagradini S. Reunión internacional meningococo w-135. Vigilancia de meningococo - Situación en Argentina (publicación en línea). Disponible en URL: http://www.paho.org/ chi/images/PDFs/sandra\%20sagradil.pdf?ua=1 (ultimo acceso julio 2017).

3. Prevención de la enfermedad meningocócica: vacunas disponibles (publicación en línea). Comité Nacional de Infectología. Sociedad Argentina de Pediatría. Disponible en URL: http://www.sap.org.ar/docs/enfermedadMeningococcica17-4-14.pdf (último acceso julio 2017).

4. Disposición 0144. ANMAT. Buenos Aires, 09/01/2012. Disponible en URL: http://www.anmat.gov.ar/boletin_anmat/enero_2012/Dispo_0144-12.pdf (último acceso julio 2017). 5. Disposición 6376. ANMAT. Buenos Aires, 23/10/2013. Disponible en URL: http://www.anmat.gov.ar/boletin anmat/octubre 2013/Dispo 6376-13.pdf (último acceso julio 2017). 6- Calendario Nacional de Vacunación. Ciudad Autónoma de Buenos Aires, Argentina: Ministerio de Salud de la Nación; 2017. Disponible en: http://www.msal.gob.ar/dicei/index. php/ciudadanos/calendario-de-vacunacion-interactivo (último acceso julio 2017).
} 